\title{
Kugel Ball as an Interesting Application of Designing the Hydrosphere
}

\author{
Ahmad Waguih Yacout Elescandarany \\ Mechanical Department, Faculty of Engineering, Alexandria University, Alexandria, Egypt \\ Email address: \\ awaguih@yahoo.com \\ To cite this article: \\ Ahmad Waguih Yacout Elescandarany. Kugel Ball as an Interesting Application of Designing the Hydrosphere. International Journal of \\ Mechanical Engineering and Applications. Vol. 9, No. 1, 2021, pp. 25-32. doi: 10.11648/j.ijmea.20210901.15
}

Received: February 3, 2021; Accepted: February 14, 2021; Published: March 10, 2021

\begin{abstract}
Analytical solutions are not available for the partial hemispherical hydrosphere which called as the Kugel ball fountain or the Kugel ball. However, this study offers a comprehensive idea about this phenomenon presenting a design map that gives a panoramic sight enabling the designers to easily choose whatever specifications needed for their fountain. Through simplifying the author previous formulae for this type of bearings, this paper removes the mystery of the Kugel ball phenomenon and shows that no complicated mathematic or physics are needed, as believed, to be grasped for producing such fountains. A new simple design technique is used and the most two famous fountains (at the House of Science in Patras, Greece and the largest at the Science Museum of Virginia, Richmond, USA.) are checked as an application of this design. One of the most important side results of this study is finding the equilibrium point, discovered in the author previous papers, which was considered as the equilibrium point between the forces of centripetal inertia, viscosity and friction due to the surface roughness. It becomes clear that this point is a natural characteristic of this type of bearings.
\end{abstract}

Keywords: Kugel Ball Mathematics, Externally Pressurized Bearings, Spherical Bearings, Surface Roughness, Hydrostatic Bearings Design

\section{Introduction}

Kugel ball, as defined in the fountain Wikipedia, is a water feature or sculpture where a sphere sits in a fitted hollow in a pedestal, and is supported by aquaplaning on a thin film of water. Pressurized water flows between the sphere and socket, creating a mechanical hydrostatic bearing that is nearly frictionless. The sphere can weigh thousands of kilograms, but the efficient bearing allows it to be spun by the force of a hand. The sphere does not float, being denser than water; it is often made from granite. The hydraulics of the fountain can be controlled so that the axis of rotation of the sphere changes continually [1]. To understand the Kugel ball phenomenon it is necessary to go back to the first hydrosphere found by Shaw and Strang [2] where it was suggested through theoretical and experimental work that the lubricant inertia could explain the performance of the bearing. Block and Cameron [3] disputed Shaw and Strang suggestion putting forward approximate calculations to support their view. Dowson and Taylor $[4,5]$ offered a more complete theoretical analysis by starting with the equations of motion and reducing them to a usable form retaining only the centripetal inertia terms. Yacout [6-11] developed Dowson form to be able to handle this type of bearings with its different configurations, in presence of the surface roughness centripetal inertia and the lubricant variable viscosity, investigating its performance in details and offering a single equation covers this type and a design for restricted and self-restriction fitted bearing, which the Kugel ball is to be considered a partially hemispherical configuration of the hydrosphere. Snoeijer and Weele [12] offered mathematical analysis for the Kugel ball and concluded that, as a matter of fact, the kugel fountain can be thought of as a giant ball bearing. D'Alessio and Pascal [13] offered analytical investigation of the steady flow of a thin fluid layer over a sphere resulting from a constant discharge from a small hole at the top of the sphere concluding that the technique and approach adopted can be used to model other thin flows that occur in similar settings. Michal Michalec et al [14] and Zhifeng Liu et al [15] offered a useful panoramic approach through reviews handling the hydrostatic bearings/systems of different types. The reviews went through the bearings /systems researches, design, optimization and applications. Inasmuch as the hydrosphere has been found, the arguments about this type of bearings have not 
been stopped; however, the present study mainly offers a new technique for designing the Kugel ball as a partially hemispherical hydrostatic thrust spherical bearing.

\section{Expressions Needed}

Simplifying the expressions in Yacout (6-11) gives the simplest forms of the equations needed for the Kugel ball at the appendix, which cover the un-recessed fitted hydrosphere. Equating the parameter: $\left(K_{r}, K_{c}, K_{v}, S\right.$, ) with zero for unrecessed stationary fitted bearing supplied with constant viscosity lubricant, the expressions become surprisingly simple:

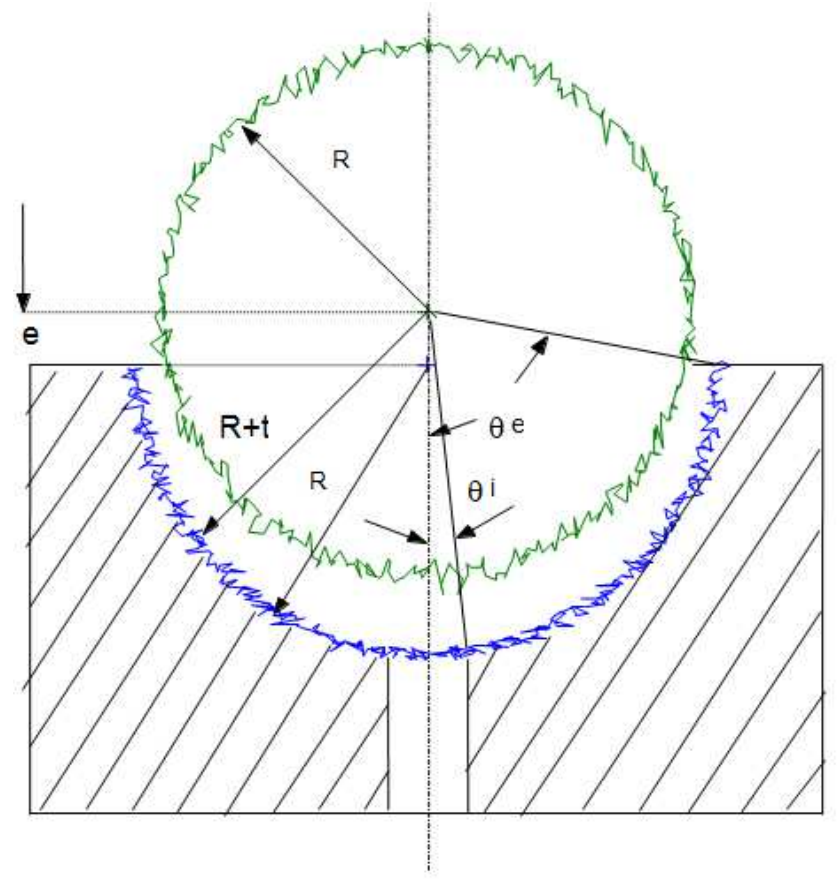

Figure 1. Bearing configuration.

\subsection{Dimensionless Pressure}

$$
P=\frac{A}{1+b^{2}}\left[\frac{1}{2 b^{2}} \ln \left(1+b^{2} \sec ^{2} \theta\right)+\ln (\tan \theta)\right]+B
$$

Where:

$$
\begin{gathered}
A=\frac{\left(1+b^{2}\right)}{\frac{1}{2 b^{2}} \ln \left(\frac{1+b^{2} \sec ^{2} \theta_{i}}{1+b^{2} \sec ^{2} \theta_{e}}\right)+\ln \left(\frac{\tan \theta_{i}}{\tan \theta_{e}}\right)} \\
B=-\frac{A}{1+b^{2}}\left[\frac{1}{2 b^{2}} \ln \left(1+b^{2} \sec ^{2} \theta_{e}\right)+\ln \left(\tan \theta_{e}\right)\right]
\end{gathered}
$$

\subsection{Dimensionless Load Carrying Capacity}

$$
\begin{aligned}
W= & \sin ^{2} \theta_{i}+\frac{A}{2 b^{2}\left(1+b^{2}\right)}\left[\left(\cos ^{2} \theta+b^{2}\right) \ln \left(\cos ^{2} \theta+b^{2}\right)\right. \\
& \left.-\frac{\sin ^{2} \theta}{1+b^{2}} \ln (\sin \theta)-\frac{\left(\cos ^{2} \theta\right)}{b^{2}} \ln (\cos \theta)\right]_{\theta_{i}}^{\theta_{e}}+B\left[\cos ^{2} \theta\right]_{\theta_{i}}^{\theta_{e}} \\
W & =w / \pi R^{2} \beta p_{s}
\end{aligned}
$$

\subsection{Dimensionless Rotational Torque}

$$
\begin{gathered}
M=\left[\frac{(\cos \theta)^{2}}{2}+\left(\sigma^{2}-1\right) \ln (\cos \theta)+\frac{\sigma^{2}}{2(\cos \theta)^{2}}\right]_{\theta_{i}}^{\theta_{e}} \\
M=m e / 2 \pi \mu \Omega R^{4}
\end{gathered}
$$

\subsection{Dimensionless Flow Rate}

$$
\begin{aligned}
& Q=-A=6 \mu q / \pi e^{3} \beta p_{s} \\
& q=K_{o r} \sqrt{(1-\beta) p_{s}} \\
& K_{o r}=\sqrt{C_{d} \pi m_{o r} d_{i o} / 8 \rho} \\
& d_{i o}=R \sin \left(\phi_{i}\right) \& m_{o r}=d_{o r} / d_{i o}
\end{aligned}
$$

\section{Kugel Ball Mathematics}

\subsection{Supply Pressure}

From eq. (4):

$$
\begin{aligned}
W & =(4 / 3) \pi R^{3} \gamma / \pi R^{2} \beta p_{s} \\
p_{s} & =(2 / 3 \beta) D \gamma J_{f}
\end{aligned}
$$

\subsection{Ball Design Parameter (bdp)}

From eq. $(7,8)$ :

$$
J_{f} Q^{2}=\frac{54 \mu^{2} K_{o r}^{2}(1-\beta)}{\pi^{2} e^{6} D \gamma \beta}
$$

\subsection{Ball Rotation}

From eq. (6):

$$
\Omega=m e / 2 \pi \mu M R^{4}
$$

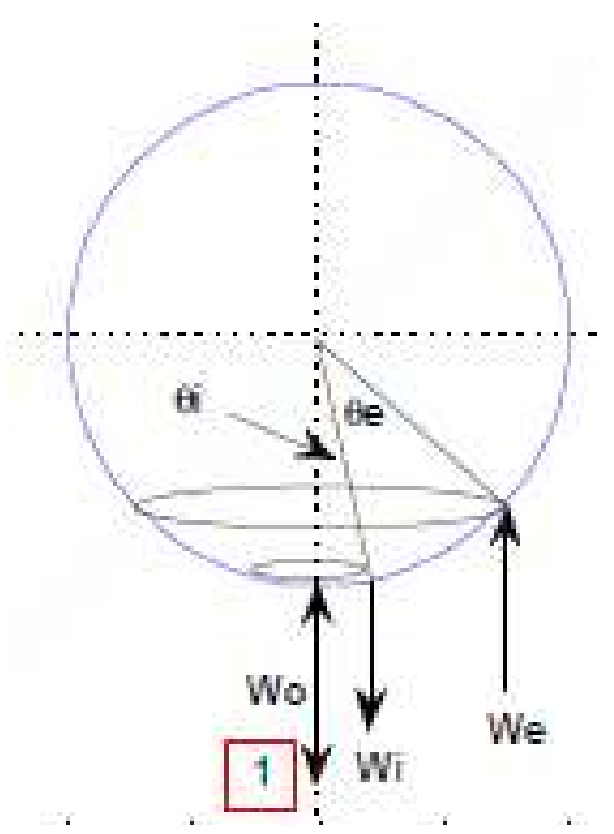




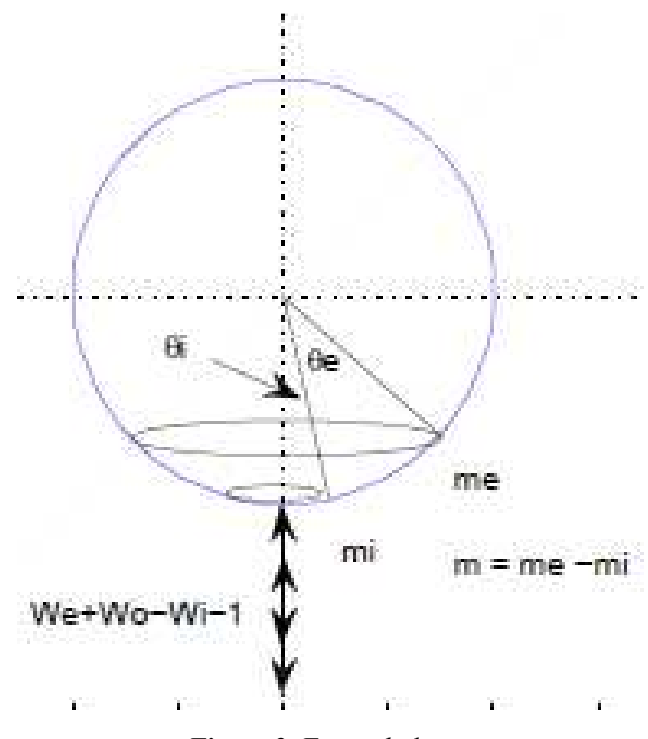

Figure 2. Forces balance.

Reforming eq. (4) becomes:

$$
\begin{aligned}
W= & W_{o}+W_{e}-W_{i} \\
W_{o} & =\sin ^{2} \theta_{i} \\
W_{e} & =\frac{A}{2 b^{2}\left(1+b^{2}\right)}\left[\left(\cos ^{2} \theta_{e}+b^{2}\right) \ln \left(\cos ^{2} \theta_{e}+b^{2}\right)\right. \\
& \left.-\frac{\sin ^{2} \theta_{e}}{1+b^{2}} \ln \left(\sin \theta_{e}\right)-\frac{\left(\cos ^{2} \theta_{e}\right)}{b^{2}} \ln \left(\cos \theta_{e}\right)\right]+B \cos \theta_{e} \\
W_{i}= & \frac{A}{2 b^{2}\left(1+b^{2}\right)}\left[\left(\cos ^{2} \theta_{i}+b^{2}\right) \ln \left(\cos ^{2} \theta_{i}+b^{2}\right)\right. \\
& \left.-\frac{\sin ^{2} \theta_{i}}{1+b^{2}} \ln \left(\sin \theta_{i}\right)-\frac{\left(\cos ^{2} \theta_{i}\right)}{b^{2}} \ln \left(\cos \theta_{i}\right)\right]+B \cos \theta_{i}
\end{aligned}
$$

From figure 2:

Balancing the forces gives:

$$
\begin{aligned}
& m=m_{e}-m_{i} \\
& m_{e}=W_{e} R \sin \theta_{e} \\
& m_{i}=W_{i} R \sin \theta_{i}
\end{aligned}
$$

3.4. Moment Due to Lateral Dislocation of the Ball Center

$$
m_{w}=w e_{l}
$$

\subsection{The Lubricant Film Thickness}

$$
\begin{aligned}
& h_{e}=e \cos \theta_{e} \\
& h_{i}=e \cos \theta_{i}
\end{aligned}
$$

\section{Design Procedures}

The ball diameter is (D) and its specific weight is $(\gamma)$

Then:

Select the parameters of $\left(e, \phi_{i}, \beta, m_{o r}\right)$

Draw $\left(J_{f}\right)$ at different values of $(\eta)$

Draw $(\Omega)$ or $(N)$ at different values of $(\eta)$
Draw $\left(J_{f} Q^{2}\right)$ at different values of $(\eta)$ i.e., the graph $(j f q c-\eta)$ or the suggested name (bdp) graph.

Calculate the ball $\left(J_{f} Q^{2}\right)$ based on the selected parameters i.e., (JFQ)

The intersection between the calculated (JFQ) with the drawn graph $(j f q c-\eta)$ gives the required $(\eta)$.

By this determined $(\eta)$ find the $\left(J_{f}\right)$ graphically from the curve $\left(J_{f}-\eta\right)$

Determining $\left(J_{f}\right)$ the supply pressure $\left(p_{s}\right)$ could be calculated from equation (8).

Getting $\left(p_{s}\right)$ the flow rate $(q)$ could be calculated from equation (7).

The ball rotational speed $(N)$ could be calculated from equation (10) or graphically from the $(N-\eta)$ graph.

The minimum and maximum lubricant film thicknesses could be calculated from equation (14).

Calculate the ball center dislocation $\left(e_{l}\right)$ through equating the two moments in equations $(12,13)$.
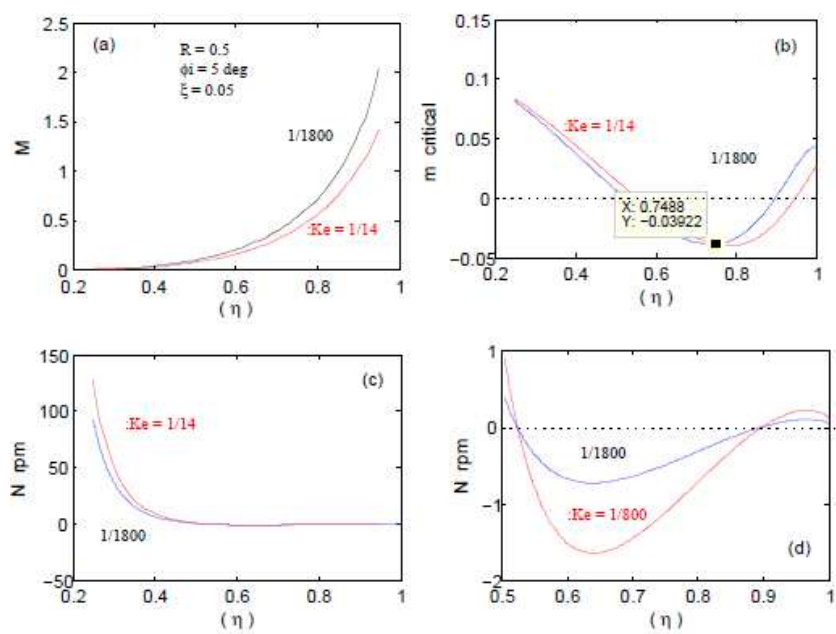

Figure 3. Bearing Characteristics.
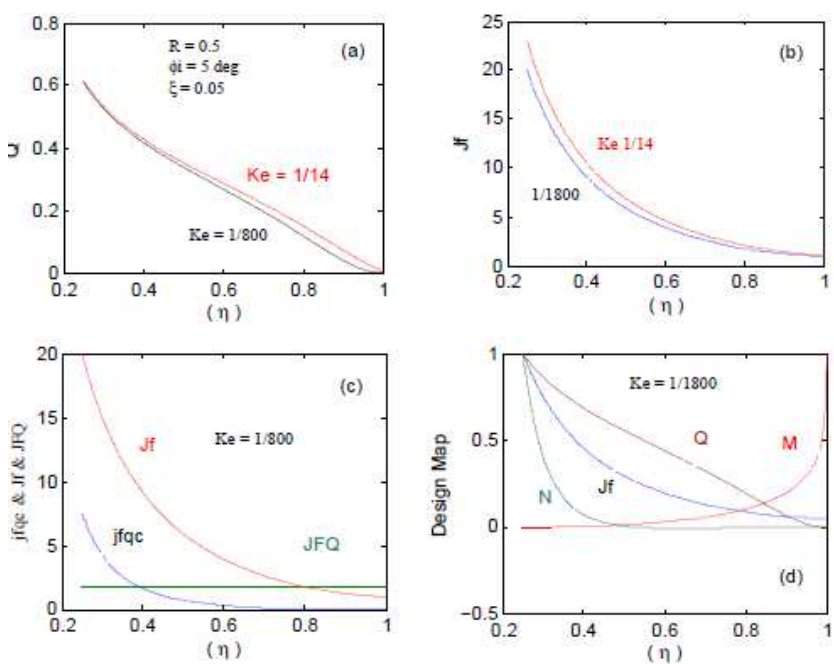

Figure 4. Bearing Characteristics. 


\section{Design Examples}

\subsection{Checking the House of Science Fountain in Patras, Greece}

The fountain specifications are:

Ball radius $(\mathrm{R})=0.5 \mathrm{~m}$ fitted with the seat.

Material, granite, specific weight $(\gamma)=2.75 \times 10^{4} \mathrm{~N} / \mathrm{m}^{3}$

Following the previous design procedures:

$\phi_{i}=2.31 \mathrm{deg}, \mathrm{K}_{\mathrm{e}}=1 / 775, \mathrm{~m}_{\mathrm{or}}=1$ for self-restriction [11] and $\beta=2 / 3$ for consistency [6-11], water lubricant $\rho=10^{3} \mathrm{Kg} / \mathrm{m}^{3}, \mu=0.001 \mathrm{~N} . \mathrm{s}^{2} / \mathrm{m}^{4}$

From eq. (7):

$$
\begin{aligned}
& K_{o r}=\sqrt{C_{d} \pi m_{o r} d_{i o} / 8 \rho} \\
& d_{i o}=R \sin \left(\phi_{i}\right)
\end{aligned}
$$

$\mathrm{K}_{\text {or }}=\{0.6 \times(22 / 7) \mathrm{x}(1) \mathrm{x}[0.5 \mathrm{x} \sin (2.31)] /(8 \times 0.001)\}^{1 / 2}$ $=8.5593 \times 10^{-6}$

From eq. (10):

$$
\begin{gathered}
J_{f} Q^{2}=\frac{54 \mu^{2} K_{o}^{2}(1-\beta)}{\pi^{2} e^{6} D \gamma \beta} \\
=54 \times(0.001)^{2} \times(8.5593 \mathrm{e}-06)^{2} \times[1(-2 / 3)] / \\
\left\{(22 / 7)^{2} \times(0.5 / 775)^{6}(1) \times\left(2,75 \times 10^{4}\right) \times(2 / 3)=0.1011\right. \\
J F Q=0.1011
\end{gathered}
$$

From figure $(j f q c-\eta)$, the intersection between the (JFQ) and the (jfqc) gives:

$$
\eta=0.6887
$$

From figure $\left(J_{f}-\eta\right)$ or from equation (4) where $\left(J_{f}=1 / W\right)$ the geometry factor could be known mathematically or graphically as:

$$
\mathrm{J}_{\mathrm{f}}=3.1868
$$

From equation (8):

$$
\begin{gathered}
\mathrm{P}_{\mathrm{s}}=(2 / 3 \times 3 / 2) \times(1) \times\left(2.75 \times 10^{4}\right) \times(3.1868) \\
=8.763 \times 10^{4} \mathrm{~N} / \mathrm{m}^{2} \\
\mathrm{P}_{\mathrm{s}}=0.8763 \text { Atmosphere }
\end{gathered}
$$

Ball weight $(\mathrm{w})=1.4399 \times 10^{4} \mathrm{~N}$

From equation (7):

$$
\begin{gathered}
\mathrm{q}=\left(8.5593 \times 10^{-6}\right) \times\left\{[1-(2 / 3)] \times \mathrm{p}_{\mathrm{s}}\right\}^{1 / 2} \\
=0.001468 \mathrm{~m}^{3} / \mathrm{s} \\
\mathrm{q}=1.468 \mathrm{Liter} / \mathrm{s}
\end{gathered}
$$

From equation (14):

$$
h_{e}=e \cos \theta_{e}
$$

$$
\begin{gathered}
h_{i}=e \cos \theta_{i} \\
\phi_{i}=2.31 \mathrm{deg} \\
\phi_{b}=\eta x \pi / 2=0.6887 \times 90=62 \mathrm{deg}
\end{gathered}
$$

The difference between $(\phi \& \theta)$ could be neglected or could be found, in details, in yacout [10] which gives:

$$
\begin{gathered}
\theta_{i}=2.307 \mathrm{deg} \\
\theta_{e}=61.9178 d e g \\
\mathrm{e}=\mathrm{R} \times \mathrm{K}_{\mathrm{e}}=(0.5 \times 1 / 775) \times 10^{6}=645.16 \text { micron } \\
h_{i}=e \cos \theta_{i}=645.16 \times \cos (2.307)=644.64 \text { micron } \\
h_{e}=e \cos \theta_{e}=645 \times \cos (61.9178)=303.7 \text { micron } \\
\mathrm{h}_{\mathrm{i}}=644.64 \text { micron } \\
\mathrm{h}_{\mathrm{e}}=303.7 \text { micron }
\end{gathered}
$$

From equations $(5,9,11$ and 12$)$ the rotational speed could be mathematically calculated or graphically through $(M-\eta)$ and $(M-\eta)$ graphs.

$$
\begin{gathered}
\mathrm{m}=0.041 \mathrm{~N} . \mathrm{m} \\
\mathrm{M}=0.3644 \\
\mathrm{~N}=-1.7645 \text { rpm (A. C. W. })
\end{gathered}
$$

From equations (13):

$$
\mathrm{e}_{\mathrm{l}}=\mathrm{m} / \mathrm{w}=\left(0.041 / 1.4399 \times 10^{4}\right) \times 10^{6}=2.846 \text { micron }
$$

$$
\mathrm{e}_{1}=2.846 \text { micron }
$$
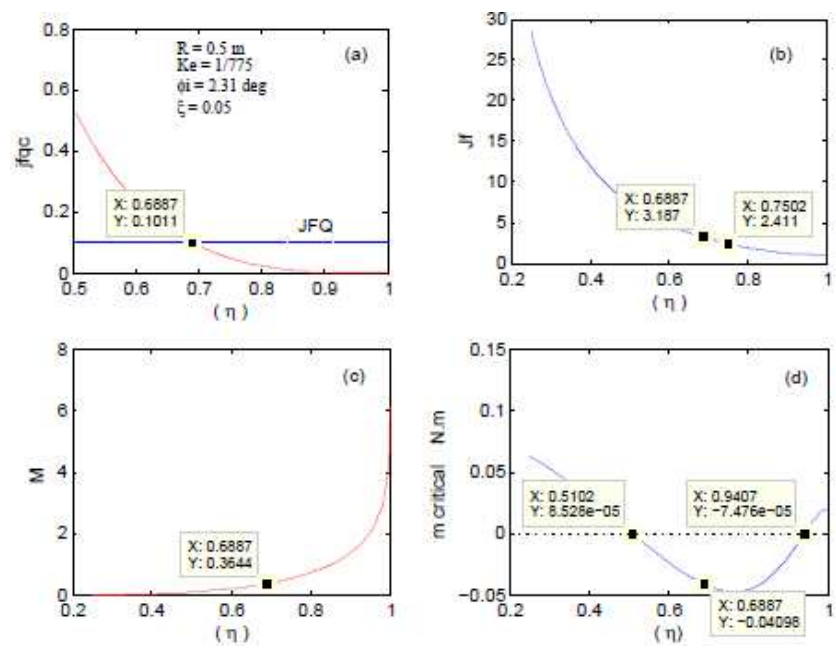

Figure 5. Design Example 1.

\subsection{Checking Virginia Museum Fountain in Richmond, USA}

The main difference between this example and the previous one is the ball stagnation.

The fountain specifications 
It has the same previous specifications excep the ball radius.

Ball radius $=1.5 \mathrm{~m}$

Starting with the selection of:

$\phi_{i}=2.31 \mathrm{deg}$, mor $=1, \beta=2 / 3$ and with aid of subfigure (3-b) select $\mathrm{Ke}=1 / 1750$, which gives the minimum $(\eta)$ that satisfies the condition of $(\mathrm{m}=0)$, i.e., no rotation, the figures (8-10) could be drawn and all needed information could be got as before either mathematically or graphically.
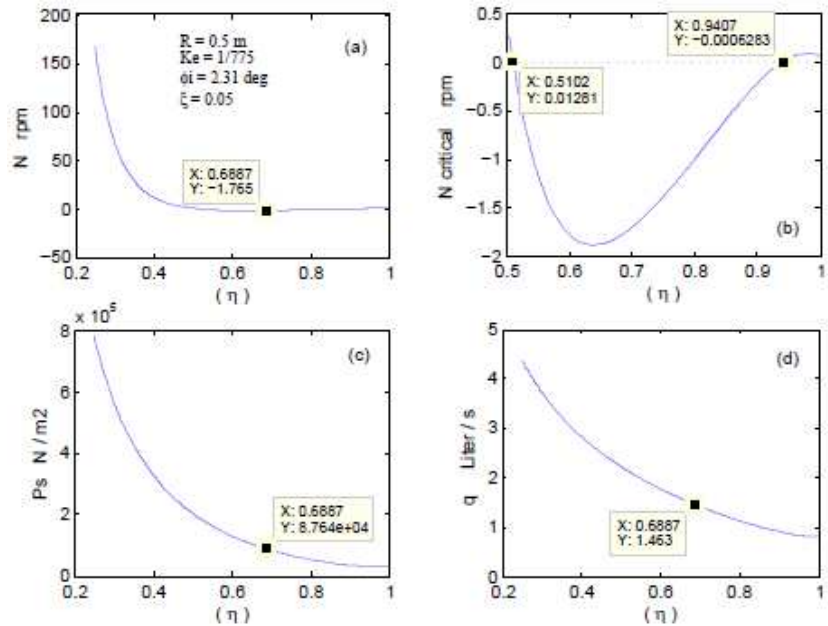

Figure 6. Design Example 1.

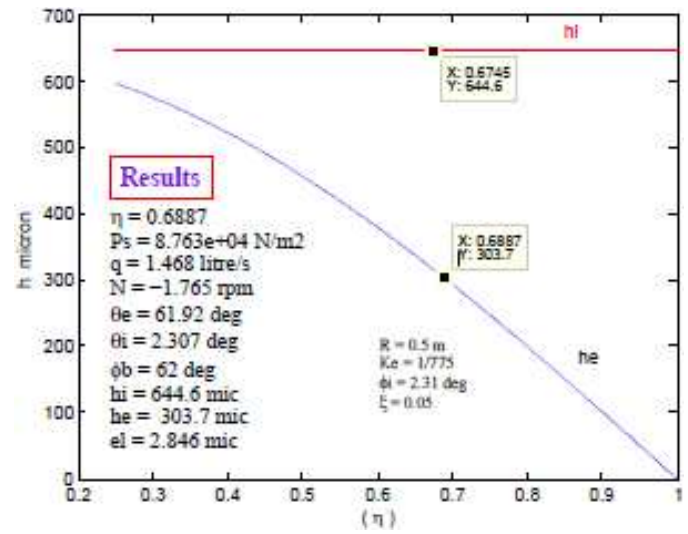

Figure 7. Design Example 1.
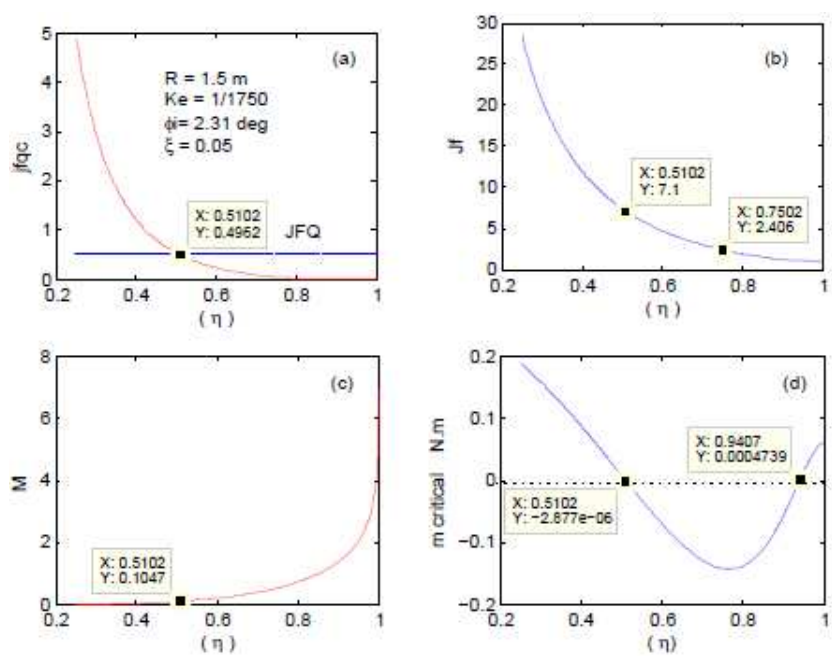

Figure 8. Design Example 2.
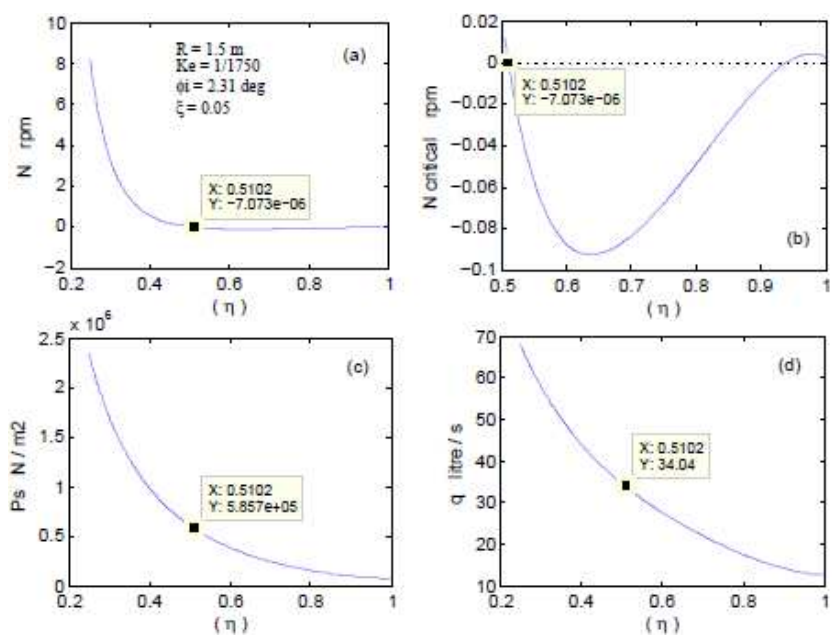

Figure 9. Design Example 2.

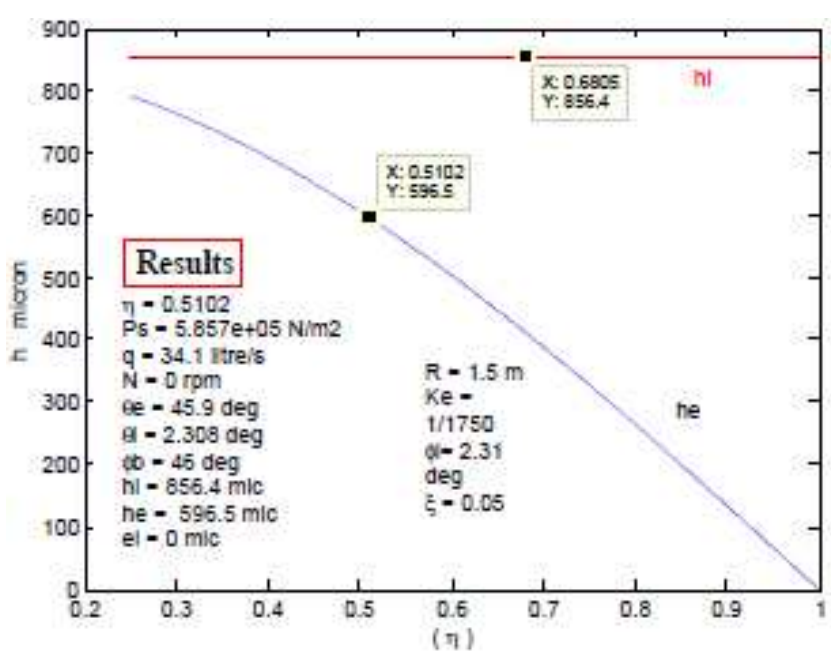

Figure 10. Design Example 2.

\section{Results}

The Kugel ball is treated as an un-recessed fitted selfrestriction hydrosphere trough a new design technique simplifying the hydrosphere formulae and developing two especial simple characteristic equations governing the kugel ball design.

A side result of this study is finding the partially hydrosphere, equilibrium point which was believed to be as the point of balance between the centripetal inertia, the viscosity and the surface roughness friction forces.

\section{Descution}

The new provided design technique simplifies the fitted hydrosphere phormaulae deriving the two characteristic equations $(8,9)$ especially for this pattern of the fitted hydrosphere.

Equation (8) simply calclates the pressure supply through multiplying the the ball diameter by its specific weight and the bearing geometry factor. 
Equation (10) is a master govering relation where it could be really defined as the bearing or the ball design parameter (bdp); it cobines the geometry factor with the dimensionless flow rate in a simple form yeilding a constant value.

\subsection{General Ball Characteristics}

Figures $(3,4)$ show the ball behavior at different partial seats and different eccentricities.

Subfigure (3-a) shows that the dimensionless rotational torque $(M)$ increases with $(\eta)$ and decreases with $(e)$ which is supported by Yacout [6].

Subfigure (3-b) is new and could be considered as an important side result of this study and will be discussed in details later on, however, it enables the designer to know the parameter $(\eta)$ that makes the ball stagnant.

Subfigures (3-c, d) show the ball rotational speed and the $(\eta)$ range that the ball changes its rotational direction.

Subfigures (4-a) shows that the dimensionless flow rate decreases with $(\eta)$ while increases with $(e)$, supported by yacout [6-11].

Subfigures (4-b) shows the geometry factor $\left(J_{f}\right)$ where it decreases with $(\eta)$ and increases with (e) which is logic where $\left(J_{f}=1 / W\right)$ and $(W)$ increases with $(\eta)$ and decreases with $(e)$, supported by Yacout [10-11].

Subfigures (4-c) show the intersection between the (JFQ) parameter of the designed ball with the $\left(J_{f}\right)$ curve to determine $\left(Q^{2}\right)$ and with (jfqc) curve to determine $(\eta)$,

Subfigures (4-d) show a design map that gives a panoramic sight on the ball behavior to enable the designer to quickly choose the area of his work.

\subsection{Checking the First Example}

Figures (5, 6 and 7) represent the first design example procedures and calculations.

From subfigure (5-a) the parameter $(\eta)$ is determined; then, after getting $(\eta)$, the geometry factor $\left(J_{f}\right)$ is determined from subfigure (5-b).

After getting $(\eta)$ and $\left(J_{f}\right)$, the pressure supply $\left(p_{s}\right)$, the flow rate $(q)$, the rotational speed $(N)$ and other specifications have bee got mathematically and also graphically.

Subfigures (5-d) and (6-b) show the designer the ability to design a stagnant ball.

Subfigures (6-c,d), represent the supply pressure and the flow rate where ( $p_{s}$ and $\left.q\right)$ could be easily determined graphically.

Figure (7) represent the lubricant film thicknesses at its inlet and outlet where the thickness could be graphically determined.

Looking at the few data mentioned by Snoeijer and van der Weele [12] about this example, it could be realized the agreement with the present results. However, despite the lack ofinformation about the specificationsof this example, the results reveal that the Kugel ball is a self-restriction hydrosphere Yacout [11].

\subsection{Checking the Second Example}

Figures (8-10) represent the second design example procedures and calculations.

In this example the ball is stagnant, hence, figure (3-b) is nessary to get the idea about the parameter $(\eta)$ that could result in the zero moment then the same procedures are to be applied as before to get the results mathematically or graphically as shown in the first example.

Due to the absence of data about this example, the present results could be considered as a temporary guide for the future investigations.

\subsection{The Side Result}

The side result got in this study is the point of minimum moment, subfigures (3-b); this point appears in yacout [6-8] which considered as the equilibrium point between the forces of the centripetal inertia, viscosity and surface roughness friction.

This point of minimum moment appears around $(\eta)$ value of (0.75). From subfigures (5-b) and (8-b), the geometry factor at this point is $(2.406-2.411)$ and its load carrying capacity $(\mathrm{W} \sim 0.416)$ which coincides with the equilibrium point of the fitted hydrosphere in yacout [6].

It becomes clearly now that the name of this point and the reason of its appearance is not the balance between the aforementioned forces and it could be assured that the point's name is the minimum moment and the reason is the minimum difference between $\left(\mathrm{m}_{\mathrm{o}}\right.$ and $\left.\mathrm{m}_{\mathrm{i}}\right)$ where the centripetal inertia will not affect this difference despite its effect on the load carrying capacity (W).

\section{Conclusion}

The new design technique has many advantages where it:

Results in deriving two simple characteristic relations where the first is concerned with the supply pressure and the second with the flow rate. While the first one is especially for the Kugel ball, the second one could be generally applied to the hydrosphere where no hydrosphere could be outside this relation.

Proves that the Kugel ball is just a simple hydrosphere based on simple mathematics not as believed before

Offers the mathematical reason of the ball rotation calculating its rotational speed whilst the concerned references treated the rotation or (spin as said in these references) as to be as a postulate

Proves that the lubricant film is not a sheet as believed and mentioned in the references but a convergent shape with different thicknesses

Finds, as a side result, the real reason of what is called the forces equilibrium point of the hydrosphere.

Offers a design map of panoramic sight on the ball characteristics to help the designer select the needed specifications

Show clearly, through the two design examples, that the 
increase in the seat arc length decreases the supply pressure which leads to levitate the ball by low pressure.

\section{Future Work}

Based on the conception of this especial hydrosphere, a general new design technique will be offered to simply design the externally pressurized thrust spherical hydrostatic bearings avoiding the difficulties in the previous designs and improving the method of selecting the proper bearing.

\section{Appendix}

All mathematical equations related to the hydrosphere could be found in Yacout [6-11] and the necessary ones which serve this design are listed.

\section{Appendix 1. Dimensionless Pressure}

$$
\begin{gathered}
P=\frac{A}{1+b^{2}}\left[\frac{1}{2 b^{2}} \ln \left(1+b^{2} \sec ^{2} \theta\right)+\ln (\tan \theta)\right]-2 S \cos ^{2} \theta+B \\
A=\frac{\left(1+b^{2}\right)\left[1-2 S\left(\cos ^{2} \theta_{e}-\cos ^{2} \theta_{i}\right)\right]}{\frac{1}{2 b^{2}} \ln \left(\frac{1+b^{2} \sec ^{2} \theta_{i}}{1+b^{2} \sec ^{2} \theta_{e}}\right)+\ln \left(\frac{\tan \theta_{i}}{\tan \theta_{e}}\right)}
\end{gathered}
$$$$
B=2 S \cos ^{2} \theta_{e}-\frac{A}{1+b^{2}}\left[\frac{1}{2 b^{2}} \ln \left(1+b^{2} \sec ^{2} \theta_{e}\right)+\ln \left(\tan \theta_{e}\right)\right]
$$

\section{Appendix 2. Dimensionless Load Carrying}

$$
\begin{aligned}
& W=\sin ^{2} \theta_{i} \\
& +\frac{A}{2 b^{2}\left(1+b^{2}\right)}\left[\left(\cos ^{2} \theta+b^{2}\right) \ln \left(\cos ^{2} \theta+b^{2}\right)-\frac{\sin ^{2} \theta}{1+b^{2}} \ln (\sin \theta)\right. \\
& \left.\quad \quad-\frac{\left(\cos ^{2} \theta\right)}{b^{2}} \ln (\cos \theta)\right]_{\theta_{i}}^{\theta_{e}}-S\left[\cos ^{4} \theta\right]_{\theta_{i}}^{\theta_{e}}+B\left[\cos ^{2} \theta\right]_{\theta_{i}}^{\theta_{e}} \\
& W=w / \pi R^{2} \beta p_{s}
\end{aligned}
$$

\section{Appendix 3. Dimensionless Rotational Torque}

$$
\begin{aligned}
M= & {\left[\frac{(\cos \theta)^{2}}{2}+\left(\sigma^{2}-1\right) \ln (\cos \theta)+\frac{\sigma^{2}}{2(\cos \theta)^{2}}\right]_{\theta_{i}}^{\theta_{e}} } \\
& M=m e / 2 \pi \mu \Omega R^{4}
\end{aligned}
$$

\section{Appendix 4. Dimensionless Flow Rate}

$$
\begin{aligned}
& Q=-A=6 \mu q / \pi e^{3} \beta p_{s} \\
& q=K_{o r} \sqrt{(1-\beta) p_{s}} \\
& K_{o r}=\sqrt{C_{d} \pi m_{o} d_{i o} / 8 \rho} \\
& d_{i o}=R \sin \left(\phi_{i}\right) \\
& m_{o r}=d_{o r} / d_{i o}
\end{aligned}
$$

\section{Appendix 5. The Lubricant Film Thickness}

$$
\begin{aligned}
& h_{e}=e \cos \theta_{e} \\
& h_{i}=e \cos \theta_{i}
\end{aligned}
$$

\section{Appendix 6. Geometry Factor}

$$
J_{f}=1 / W
$$

\section{Nomenclature}

$A=-\left(6 \mu q / e^{3} \pi p_{i}\right)$

$a=$ Bearing projected area $\left(\pi R^{2}\right)$.

$b^{2}=3 \sigma^{2}$

$D=$ Ball diameter

$d_{o r}=$ Orifice restrictor diameter

$d_{i o}=$ Bearing inlet orifice diameter.

$e=$ Eccentricity.

$e_{l}=$ Lateral eccentricity (dislocation)

$h=$ Film thickness $=e \cos \theta$

$h_{e}=e \cos \theta_{e}$

$h_{i}=e \cos \theta_{i}$

$J_{f}=$ Geometry factor $=1 / \mathrm{W}$

$J F Q=J_{f} Q^{2}$ For the ball

$j f q c=J_{f} Q_{\eta}^{2}$ For the ball at different $(\eta)$

$K_{\mathrm{e}}=(e / R)$

$K_{\text {or }}=$ Orifice restrictor constant

$M=$ Dimensionless torque $\left(\frac{m e}{2 \pi \mu \Omega R^{4}}\right)$.

$m=$ Rotational torque.

$m_{o r}=d_{o r} / d_{i o}$

$m_{w}=$ The moment due to the ball center dislocation

$N=$ Rotational speed (rpm)

$p_{i}=$ Inlet pressure

$p_{s}=$ Supply pressure

$q=$ lubricant volume flow rate

$R=$ Ball radius.

$W=$ Dimensionless load carrying capacity $\left(w / \pi R^{2} p_{i}\right)$.

$w=$ Ball weight.

$\beta=p_{i} / p_{s}$

$\varphi_{b}=$ Seat outer rim angle.

$\varphi_{i}=$ Seat inner rim angle.

$\theta=$ Angle co-ordinate.

$\theta_{i}=$ Inlet flow angle.

$\theta_{\mathrm{e}}=$ Outlet flow angle.

$\rho=$ Lubricant density $\left(1000 \mathrm{~N} . \mathrm{s}^{2 /} \mathrm{m}^{4}\right)$.

$\sigma=$ Dimensionless surface roughness parameter.

$\sigma_{o}^{2}=$ Variance of the film thickness.

$\Lambda=\left(h_{\min } / \sigma\right)$ Dimensionless film thickness parameter (5:100) for the hydrodynamic lubrication regime.

$\gamma=$ Specific weight of the ball material $2.75 \times 10^{4} \mathrm{~N} / \mathrm{m}^{3}$ $\eta=2 \phi_{b} / \pi$

$\xi=$ Normalized roughness Parameter (0.05:1) 
$\lambda=$ Bearing stiffness.

$\mu=$ Lubricant viscosity $\left(0.001 \mathrm{~N} . \mathrm{s} / \mathrm{m}^{2}\right)$

$\Omega=2 \pi N$

\section{References}

[1] Fountain https://en.wikipedia.org/wiki/Kugel_fountain.

Wikipedia.

[2] The hydrosphere, A new hydrodynamic bearing," Shaw M. C. and Strang C. D. "The annual meeting of the American Society of Mechanical Engineers, 1948, 137-146. https://sites.google.com/umich.edu/shihlabs/prof-miltonshaw/manuscript-of-professor-milton-shaw.

[3] Discussion of Show and Strang hydrosphere, a new hydrodynamic bearing, "Block $\mathrm{H}$. and Cameron A. "Transaction of ASME J. Appl. Mech. 1949, Vol. 71, 93-102.

[4] Fluid-inertia effects in spherical hydrostatic thrust bearings, "Dowson D. and Taylor C. M. "ASLE, Transaction, 1967, 10, 3, 316-321. https://doi.org/10.1080/05698196708972189.

[5] Re-examination of hydrosphere performance, "Dowson D. and Taylor C. M. "ASLE, Transaction, 1967, 10, 3, 325-333. https://doi.org/10.1080/05698196708972189.

[6] The combined effects of the centripetal inertia and the surface roughness on the hydrostatic thrust spherical bearings performance, Ahmad W. Yacout, Ashraf S. Ismail, Sadek Z. Kassab,' Tribology International, 2007, 40 (3), 522-532. https://doi.org/10.1016/j.triboint.2006.05.007.

[7] W., Ismail A. S. and Kassab S. Z.," The Surface Roughness Effect on the Hydrostatic Thrust Spherical Bearings Performance (part 2 un-recessed clearance type), ASME International Mechanical Engineering Congress and Exposition, IMECE2006-13004. https://doi.org/10.1115/IMECE2006-13004.

[8] Yacout A. W., Ismail A. S. and Kassab S. Z.," The Surface
Roughness Effect on the Hydrostatic Thrust Spherical Bearings Performance (Part 3 recessed clearance type of bearings), "ASME International Mechanical Engineering Congress and Exposition, IMECE 2007 -41013. https://doi.org/10.1115/IMECE2007-41013.

[9] The Effect of the fluid Film variable viscosity on the hydrostatic thrust spherical bearing performance in the presence of centripetal inertia and surface roughness,' Ahmad W. Y. Elescandarany, 'International Journal of Mechanical Engineering and Applications, 2018, 6 (1), 1-12. https://doi:10.11648/j.ijmea.20180601.11.

[10] Design of the Hydrostatic thrust spherical bearing with restrictors (Fitted type), "Ahmad W. Y. Elescandarany' International, "Journal of Mechanical Engineering and $\begin{array}{lllll}\text { Applications, } & 2019, & 7 & \text { (2), }\end{array}$ https://doi:10.11648/j.ijmea.20190702.11.

[11] Design of Self-restriction Hydrostatic Thrust Spherical Bearing (Fitted Type)' Ahmad W. Y. Elescandarany' International Journal of Mechanical Engineering and $\begin{array}{llll}\text { Applications, } & 2019, & 7 & \text { (4), } \\ \end{array}$ https://doi:10.11648/j.ijmea.20190704.14.

[12] Physics of the granite sphere fountain,'Jacco H. Snoeijer and Ko van der Weele, 'American Journal of Physics 2014, 82, 1029. https://doi: 10.1119/1.4886365.

[13] The dynamics of the globe fountain, 'Serge D'Alessio and J. P. Pascal, 'AFM 2016, September 5-7, Ancona, Italy. https://doi:10.2495/cmem-V4-N2-131-141.

[14] A review of the design and optimization of large-scale hydrostatic bearing systems, "Michal Michalec, Petr Svoboda, Ivan Křupka, Martin Hartl," Engineering Science and Technology, an International Journal (JESTECH), 2021. https://doi.org/10.1016/j.jestch.2021.01.010

[15] A review of hydrostatic bearing system: Researches and applications," Zhifeng Liu, YumoWang, Ligang Cai, Yongsheng Zhao, Qiang Cheng and Xiangmin Dong, "Advances in Mechanical, Engineering 2017, Vol. 9 (10) 1-27 DOI: $10.1177 / 1687814017730536$. 